\title{
SEITAS OU O "MAL A LA FRANÇAISE": REFLEXÕES SOBRE AS OPÇÕES RELIGIOSAS NA SOCIEDADE FRANCESA CONTEMPORANEA.
}

\author{
Adriane Luisa Rodolpho (EHESS-Paris)
}

O título deste $\operatorname{artigo~}^{1}$ refere-se a duas formas de representação no âmbito do espaço religioso. Num primeiro momento, apresento o contexto francês contemporâneo com relação à questão das seitas; de certa maneira, poder-se-ia dizer que este é claramente negativo com relação às mesmas. Neste sentido, o discurso dominante é unânime em afirmar que as seitas são um perigo ao qual a sociedade e o Estado devem fazer frente. Entretanto, o grupo sobre o qual pesquisei Eckankar - considerado oficialmente como uma seita ${ }^{2}$, apresenta igualmente suas representações sobre o mal e o perigo, no seio desta mesma sociedade. Olhares que se cruzam e, de certa maneira, complementam-se.

Para se falar sobre as representações do mal em Eckankar, é necessário antes informar ao leitor acerca das práticas de crença deste grupo. A pesquisa desenvolvida ${ }^{3}$ inscreve-se como uma contribuição na discussão mais ampla sobre as conformações contemporâneas das crenças na sociedade francesa. Tomando como caso de estudo um grupo específico - Eckankar - classificado como seita pelo Rapport de l'Assemblée Nationale, a pesquisa coloca questões sobre as formas das práticas religiosas deste grupo, seu histórico, sua conformação e o lugar

\footnotetext{
1 O título do artigo faz igualmente referência explícita aos textos fundamentais presentes em Birman, P. Novaes, R. \& Crespo (1997.

${ }^{2}$ Assemblée Nationale, Rapport fait au nom de la commission d'enquête sur les sectes. (1996).

${ }^{3} \mathrm{O}$ trabalho aqui apresentado retoma minha tese de doutorado (Rodolpho, 2002).
} 
que os participantes ocupam no panorama mais vasto da sociedade urbana moderna.

Em seqüência aos estudos realizados no Brasil, as questões relativas ao domínio religioso e as problemáticas envolvendo as crenças sempre me interessaram. A possibilidade de efetuar um trabalho de etnografia religiosa, na França, foi a oportunidade de realizar um trabalho estimulante e difícil ao mesmo tempo, e que se traduz até mesmo em minha trajetória pessoal. É a partir, portanto, desta posição, enquanto etnóloga brasileira, que Eckankar foi por mim percebido como um grupo religioso entre outros: percebi as definições e as questões que envolvem as utilizações das categorias «seita»e « religião » durante o desenvolvimento da pesquisa. Este a priori (ou ausência de) permitiu-me identificar, na situação francesa, a existência nesta sociedade de um espaço de discussão, em torno das questões colocadas pela coabitação de grupos religiosos com a tradição republicana e laica, que problematiza e questiona a noção do religioso e de seu lugar na sociedade ${ }^{4}$.

Somos confrontados a um sistema de valores específico quando falamos de Eckankar. Trata-se de um sistema de representações que traz em si uma visão de mundo particular, e a questão aqui é de verificar como as práticas e as crenças são definidas e vividas pelos eckistas. Segundo os adeptos, Eckankar é uma religião de experiência ; os fiéis são confrontados a um quadro novo e diferente das percepções habituais do mundo. Os eckistas realizam a viagem da alma, um deslocamento espiritual através dos diferentes planos de existência. Uma cartografia do universo é assim estabelecida, bem como uma representação especial do corpo.

${ }^{4} \mathrm{Na}$ França, a discussão em torno das seitas é bastante ampla e a bibliografia produzida extensa. No âmbito das ciências sociais, cabe à sociologia e à história das religiões a primazia nas análises; em contrapartida, é interessante notar que a produção propriamente antropológica sobre a questão é mais restrita. Ver a respeito Champion, F. \& Cohen, M. (1999); Champion, F. et Hervieu-Léger, D. (1990); Hervieu-Léger, D. (2001), entre outros. Neste sentido, é importante salientar a relevância da bibliografia produzida por antropólogos brasileiros como Birman, P. (1999 e 2000) e Giumbelli, E. (2000). 
Eckankar possui uma organização hierárquica e está presente em mais de 100 países $^{5}$. De origem norte-americana, Eckankar se constituiu em 1965 em torno de Paul Twitchell, considerado pelos adeptos não apenas como o fundador de uma nova religião mas como o divulgador de uma antiga doutrina vinda da noite dos tempos ${ }^{6}$. A sede central, o Templo Eck, se localiza em Minneapolis, nos Estados Unidos. É lá que habita Sri Harold Klempt, o atual dirigente espiritual de Eckankar. Sri Harold é considerado como o Mestre Eck Vivo, o Mahanta, herdeiro de uma antiga linhagem espiritual e sucessor de Paul Twitchell.

Cada país possui um Resa (termo em inglês para «Regional Eck Spiritual Aid»), um responsável nacional (espiritual e administrativo) e, no caso, na França existe um casal Resa, que mora no sul do país. A França está organizada em várias regiões de Eckankar com seus coordenadores locais: região Oeste, Norte, região Ile de France, Centro, Sudeste e Sudoeste.

A organização de Eckankar se constitui portanto em torno da instância central, situada nos E.U.A., de instâncias nacionais, regionais e locais. A pesquisa centrou-se sobre o grupo Eckankar de Paris/Ile de France. Aliás, a organização é a mesma para todas as regiões, isto é, além da coordenação nacional composta pelo Resa e os responsáveis nacionais dos serviços espirituais, administrativos e dos serviços de comunicação, os responsáveis regionais são encarregados destes mesmos serviços.

A cosmologia eckista propõe ao menos doze planos de existência da alma. Numa escala de evolução espiritual, os cinco primeiros planos são considerados como inferiores, uma vez que se localizam mais próximos da matéria ; os cinco níveis seguintes iniciam os planos da alma propriamente ditos, os mundos de puro espírito. Aos

\footnotetext{
${ }^{5}$ Informações sobre a organização institucional do grupo podem ser consultados no site internet do grupo: www.eckankar-français.org.

${ }^{6}$ Paul Twitchell é considerado o $971^{\circ}$ Mestre Eck Vivo; segundo a cosmologia eckista, sempre existiu um Mestre Eck Vivo, em todos os continentes e em todos os tempos.
} 
cinco primeiros planos correspondem os corpos físico, astral, causal, mental e etérico. As correspondências são as seguintes:

"Plano físico (sentidos): plano onde a alma é presa das cinco paixões: vaidade, cupidez, cólera, apego e concupiscência. Astral (emoções): fonte dos fenômenos psíquicos - fantasmas, discos voadores, espíritos, percepções extra-sensoriais. Causal (memória): plano onde as lembranças, as tramas karmicas e os arquivos akáshicos são guardados. Mental (intelecto): fonte de todos os ensinamentos metafísicos, estéticas, filosofias, concepções ortodoxas de Deus. Consciência cósmica. Etérico (intuição): última barreira entre os mundos inferiores e o Sat Nam". "

Estes mundos inferiores são governados por Kal Niranjan, o poder maléfico em Eckankar. Considerados como os mundos menos evoluídos espiritualmente, é em seu domínio que se encontram todas as religiões, filosofias e técnicas psico-terapêuticas. Igualmente espaço da ilusão e das crenças em geral, é o mundo que o eckista deve abandonar, em vistas ao desenvolvimento de sua alma: este se dá fundamentalmente pelos conhecimentos adquiridos através do estudo da doutrina eckista e pelas práticas cotidianas de contemplação ou viagem de alma.

Para viajarem entre os diferentes planos da alma, os eckistas contam com o auxílio do Mestre Eck Vivo, responsável direto pelo desenvolvimento espiritual de cada adepto. O Mestre Eck Vivo é a personificação do divino Sugmad. O termo Eck significa a corrente sonora ou energia primordial criadora do todo; metaforicamente, é a chamada Via do Eck, estrada que o fiel deve trilhar ao lado do Mestre em direção ao re-encontro final das almas. Este espaço de criação cósmica era o antigo lar das almas, foyer original de bem estar e alegria. Entretanto, o Sugmad provoca a queda destas nos mundos inferiores da matéria; lá elas devem aprender e desenvolver-se

${ }^{7}$ In: Les Mondes de Eck (cartaz). Eckankar, 1984. 
espiritualmente. A vida é assim considerada uma escola, onde cada alma progride segundo seu próprio ritmo.

A temática da queda das almas nos mundos da matéria diz respeito a uma essência superior e espiritual, que estaria na origem da fragmentação destas almas, consideradas como centelhas divinas ou pedaços de luz. A reunião final e o encontro, no seio desta essência divina, são o objetivo destas centelhas. O esquema narrativo de concepção eckista propõe, portanto - estado original, explosão, dispersão, reconstituição, novo estado - em sua descrição da criação do mundo. Em Eckankar esta evolução constante recorre a uma linguagem aos matizes hinduístas, às respirações da divindade original criando e destruindo o universo. Neste caminho de volta através dos diferentes planos, Kal Niranjan produzirá as ilusões, lançando armadilhas para que a alma não consiga retornar ao lar original. O próprio roteiro sobre o processo de hominização é explicado em Eckankar através da luta constante contra o $\mathrm{Kal}$, o poder do intelecto e das emoções.

Algumas noções fundamentais de Eckankar aparecem nesta narrativa cosmológica, tais como a viagem da alma, a reencarnação e o karma, assim como a noção de inferioridade dos planos governados por Kal Niranjan. A narrativa é apresentada especialmente nos dois volumes do texto fundamental de Eckankar, o Shariyat-Ki-Sugmad, escritos por Paul Twitchell em 1970 e $1971^{8}$. Nestas e em outras obras delineia-se a visão apresentada por Twitchell com relação à origem do mundo e da vida humana sobre a Terra. A existência de Eckankar através dos tempos é o argumento principal do autor, em torno do qual se organiza a cosmologia eckista. Nesta, a ordem do universo é colocada ao lado de uma antropologia no sentido largo, ou seja, de uma noção de homem (de suas origens ao seu destino), assim como de uma teoria soteriológica (onde são estabelecidas as possibilidades de salvação após a morte física $)^{9}$.

Twitchell propõe uma narrativa onde três grandes conjuntos temporais podem ser identificados: um primeiro período mítico - a respiração criadora da divindade e a existência de elementos (como os

\footnotetext{
${ }^{8}$ Twitchell, P. (1970 e1971).

${ }^{9}$ Ver, neste sentido, as análises desenvolvidas por Wiktor Stoczkowski (1999 e 1994).
} 
"ovos cósmicos") lembrando a influência das noções cosmológicas do hinduísmo; em seguida, uma pré-história do planeta é proposta, seguindo-se idades e civilizações igualmente míticas (as raças dos Polarianos, Hiperboreanos e os continentes de Atlântida, Lemúria ou $\mathrm{Mu}$, entre outros). Desta vez, entretanto, o discurso pretende legitimarse de forma racionalista, apoiando-se sobre considerações que recorrem a termos e linguagens cientificistas; exemplo disto são as inúmeras referências a provas arqueológicas, passíveis de validar e demonstrar a veracidade dos acontecimentos descritos. Ao final, um período histórico é proposto, postulando a existência de Eckankar desde a origem dos tempos. Civilizações históricas tais como o Egito e a Grécia são freqüentemente citados, assim como as contribuições de várias personalidades nos diferentes domínios do conhecimento são apresentadas como o produto do trabalho dos detentores dos segredos de Eckankar, a linhagem espiritual dos Mestres Eck.

Marguerite (francesa, terapeuta e representante comercial, 75 anos e eckista de « primeira hora ») assim descreve seu encontro com Eckankar:

(...) "Eu li o livro Eckankar, a Chave dos Mundos Secretos e logo em seguida telefonei. Fiquei sabendo que nesta mesma noite, às 19 horas, haveria uma reunião " portas abertas ». Quando lá cheguei a porta se abriu, e uma senhora de olhos azuis me recebeu. Eu entrei na pequena sala e lá estava, sobre a parede, uma fotografia; eu perguntei: 'Mas quem é este homem? Eu o conheço!'A senhora ao meu lado comentou: 'Mas, você o conhece?'. 'Sim, eu o conheço', ao que ela respondeu: 'Ele é um dos Mestres Eck'. 'Desde minha infância ele vem ao meu encontro, e nós viajamos juntos. Ele me conduz pela mão direita e nós viajamos juntos, nós voamos juntos e ele me mostrou muitas coisas. Em particular, ele me mostrou a Atlântida, a Atlântida e a vida em Atlântida, as diferentes encarnações que eu tive em Atlântida e, no fim, a queda, digamos, a catástrofe do fim de Atlântida' Ela então me disse: 'venha, vou lhe mostrar o guia dos outros mestres', e ela me levou frente a um grande quadro, com o retrato de uma cinquentena de mestres, todos diferentes, todos vestidos com roupas diferentes e, ao centro, sobre uma grande coluna de luz, um mestre Eck que recebia justamente a iniciação de Mahanta. Ela nomeou todos os mestres, um após o 
outro. Durante este tempo, ela segurava minhas mãos, e nós saímos dos nossos corpos, as duas juntas. E ainda é um momento maravilhoso que eu revivo, e isto aconteceu em março de 1974“.

Eckankar é uma religião iniciática ${ }^{10}$, o que significa que o conjunto dos conhecimentos específico da doutrina deve ser apreendido pouco a pouco pelos fiéis, que passam, a partir da iniciação, por várias etapas de desenvolvimento espiritual. $\mathrm{O}$ manejo destes conhecimentos passa pelo aprendizado de vários códigos e grades de interpretação colocadas à disposição dos eckistas, e as técnicas corporais ${ }^{11}$ desempenham um importante papel nos exercícios espirituais ${ }^{12}$. Disto o papel, na doutrina eckista, da interpretação de uma vasta gama de « sintomas » que os fiéis sentem: as cores, os sons, as imagens percebidas devem ser explicados pelo biais eckista.

A especificidade da postura antropológica seguida neste estudo adota o ponto de vista de um reencontro onde as proposições analíticas finais podem ser compreendidas como um dos resultados possíveis, entre outros. A problemática que decorre da questão relativa às diferentes maneiras pelas quais os participantes crêem e manifestam suas crenças traz em si a intenção do etnólogo que procura apreender as diferentes concepções e representações sobre o universo do plausível e do possível, elaborados segundo os valores dos diversos grupos constituídos, através do diálogo e da partilha desses conhecimentos. Trata-se de examinar um lugar de reencontro com um grupo determinado, local de negociações e de aprendizagem onde os sujeitos do fato etnográfico - a saber, o

${ }^{10}$ Rapidamente, a iniciação é aqui compreendida como uma transformação cultural referente à formação de uma identidade, adquirida pelo neófito e partilhada pelos agentes de um « dentro » (o grupo em questão), este mesmo constituído por oposição a um « fora » (a sociedade circundante). Cf. Zempleni, A. (1991).

${ }^{11}$ Gostaria aqui apenas de relembrar a anedota contada par Mauss sobre as mudanças das técnicas corporais relativas à natação, transformações que ele viveu como testemunha: De plus, on a perdu l'usage d'avaler de l'eau et de la cracher. Car les nageurs se considéraient, de mon temps, comme des espèces de bateaux à vapeur. C'était stupide, mais enfin je fais encore ce geste : je ne peux pas me débarrasser de ma technique. Voilà donc une technique du corps spécifique. Mauss, M. (1983).

12 Os exercícios espirituais são as práticas quotidianas que o eckista deve realizar para despertar em si a Luz e o Som de Deus. 
etnólogo e as pessoas com quem se estabelece a partilha de um momento de suas vidas - se colocam em relação de proximidade. É esta relação e os diferentes locais onde ela se manifesta que conduzem à um momento de pesquisa, ou seja, à um espaço transitório e inacabado, constitutivo de um processo onde as distinções e os reconhecimentos podem ser examinados pelos sujeitos envolvidos ${ }^{13}$.

Inicialmente, alguns comentários se impõem quando se utilizam conceitos tão amplos e controvertidos como a noção de religião, compreendida enquanto fronteiras construídas, visando recobrir uma totalidade da experiência humana concebida diferentemente segundo as culturas. As definições da noção do religioso florescem no quadro dos estudos em ciências sociais ${ }^{14}$.

O contexto contemporâneo na França apresenta-se como um lugar de disputas e de confrontações sobre «o religioso »; em outros termos, é o local onde vários atores sociais posicionam-se para tentar definir o lugar da religião no contexto de um Estado laico e, assim, operam as legitimações sobre o que deve ser considerado como fazendo parte da esfera religiosa e sobre o que não faz parte: as «seitas ». As acusações lançadas contra as seitas, na França, demonstram a recusa em acordar o estatuto de religião a vários grupos de crenças consideradas como estando fora das grandes tradições religiosas historicamente estabelecidas: o cristianismo (o catolicismo e os protestantismos), o

${ }^{13}$ Nesse sentido são estimulantes as considerações de Marc Piault sobre o processo de «démarche-connaissance », in Piault, M. H. (2000: 271).

${ }^{14}$ Entre tantas definições, é interessante salientar a postura de Daniel Dubuisson e sua análise do conceito de religião em sua especificidade ocidental ; o autor propõe assim o termo formações cosmográficas. Suas interrogações são pertinentes quando diz: (...) Ne suffirait-il pas de considérer le concept de religion au même titre que d'autres créations intellectuelles ou artistiques de l'Occident, telles la philosophie présocratique ou la peinture cubiste, qui ne présentent pas d'équivalents exacts dans d'autres cultures? On l'étudierait comme on étudie les haïkais japonais ou certaines institutions exotiques, c'est-à-dire comme des créations humaines qu'il est légitime de considérer dans leur contexte originel, mais sans chercher à en faire pour autant les bases d'un paradigme anthropologique universel (ce qu'aucune culture, en dehors de la nôtre, n'a jamais prétendu faire avec ses propres créations) (...). In: Dubuisson, D. (1998 : 271). Esta relativização do conceito de religião é particularmente importante no contexto francês. 
judaísmo e o islamismo. É neste sentido que a categoria «religião », longe de ser um «objeto natural» da antropologia, informa sobre as relações que uma sociedade determinada estabelece com o Estado e com os diferentes componentes deste campo controvertido.

O campo religioso é aqui considerado sobretudo como um campo discursivo (isto posto, é evidente que os discursos se manifestam na prática social) onde as normas e os valores aos quais aderem os diferentes atores e as instâncias sociais concernentes se expõem; no caso francês, observa-se que a temática das seitas, desde os anos 1970 mobiliza a atenção de setores governamentais, dos representantes das Igrejas estabelecidas e de uma parcela da sociedade constituída em torno das associações anti-seitas, da imprensa em geral e dos participantes destas novas manifestações do crer (as seitas).

Ao longo deste trabalho considerei o grupo Eckankar como inserido num espaço social designado como campo de discussão, de acusações, de conflitos. Neste contexto de luta, o que está em questão é a concorrência em torno do monopólio da gestão (produção, difusão, reprodução e conservação) dos bens específicos do capital simbólico religioso. A constituição do campo é portanto paralela à despossessão objetiva do capital religioso dos não especialistas, os laicos ou profanos. O objetivo das categorias dominantes num campo é a maximização do profit (lucro/proveito/resultado), o que quer dizer chegar a obter um máximo de reconhecimento da parte dos outros clientes deste campo, mais exatamente, dos pares-concorrentes ${ }^{15}$.

A posição dos dominados é caracterizada por sua ambigüidade: se por um lado eles violam as regras do jogo, de outro eles respeitam bem as normas. É assim que o grupo Eckankar, mesmo em se colocando no campo dos detentores não legítimos de um capital religioso aceita e partilha o discurso dominante ${ }^{16}:$ no conjunto de idéias do senso comum

\footnotetext{
${ }^{15}$ Bourdieu, Pierre. (1971 e 1976).

${ }^{16}$ Os três componentes principais do discurso dominante sobre as seitas são citados por Messner quando o autor indica que : (...) Nous ne portons aucun jugement de valeur sur ces différents groupements religieux souvent violemment critiquées par des associations de lutte contre les sectes, les médias ou des institutions publiques. (...). Messner, Francis In Champion, F. \& Cohen, M. (1999).
} 
relativas ao perigo sectário, os eckistas partilham os axiomas principais da discussão (entre outros, validam a concepção da existência de seitas potencialmente maléficas). O grupo Eckankar, fazendo parte do Rapport de l'Assemblée Nationale e sendo citado na imprensa escrita, é portanto formalmente acusado de ser uma seita. Entretanto, os eckistas não se reconhecem nesta acusação. Eles a reenviam à grupos 'outros' (sem jamais os designar), passíveis, estes, de serem considerados como seitas. $\mathrm{O}$ fato de não designar um grupo particular como sendo uma seita demonstra que os eckistas partilham sobretudo com o discurso dominante a idéia da possibilidade de sua existência e, conseqüentemente, a possibilidade de que estas ocasionem o mal e o perigo.

Num contexto social assim caracterizado, como se operam as escolhas/opções das crenças? A pesquisa desenvolvida junto ao grupo Eckankar propõe assim uma reflexão sobre as características específicas de que se revestem as opções de crença na sociedade francesa contemporânea. Num quadro dominante de representações consideradas como legítimas sobre o religioso, a opção ou a escolha dos eckistas - ou de outros grupos acusados de serem seitas - é considerada pela sociedade em geral sobretudo de maneira negativa: é uma via de perdição. Trata-se de uma ausência, de um defeito ou de uma falta, seja da plena utilização das capacidades racionais ou intelectuais dos indivíduos, seja de sua estabilidade afetiva ou emocional.

Neste trabalho objetivou-se sublinhar que este local de discussão se apresenta como um espaço de conflitos conceituais. Diferentes grupos sociais, detentores de sistemas de valores específicos, se opõem e se acusam mutuamente. Esta operação de classificação é operada sobretudo pelas associações anti-seitas, pelas instâncias governamentais e pela mídia, e é também partilhada pelos eckistas. Os grupos representantes do discurso dominante sobre o religioso considerado como legítimo se afrontam sobre a identidade de numerosos movimentos religiosos, espirituais e mesmo terapêuticos.

Tratava-se, de minha parte, de um lado, de efetuar um esforço de depuração deste campo de discussão e, de outro, de fornecer racionalizações explicativas. Foi assim que me pareceu possível 
identificar o conjunto dos axiomas relativos à periculosidade das seitas, (sobretudo as premissas sobre sua capacidade de contagio maléfico através da manipulação mental) como um espaço de afirmações funcionando poderosamente como senso comum ${ }^{17}$, opinião pública ${ }^{18}$ ou ainda como uma mitologia científica ${ }^{19}$, largamente partilhado e cujos pressupostos não são quase nunca recolocados em questão.

O pertencimento ao universo do religioso, enquanto grupo definido e identificável (as religiões institucionalizadas), é percebido majoritariamente pelo discurso dominante como dando espaço à suspeição, em nome das prerrogativas laicas, mas não constitui um perigo. A partir do momento que um grupo é identificável, ele dá a impressão de poder ser assim controlável: ele não representa um perigo que o Estado ou a sociedade não possam controlar. Entretanto, na medida em que o grupo se situa fora dos limites do conhecido e do reconhecido (caso de Eckankar e de vários outros grupamentos de crenças minoritários) ele se torna passível de ser classificado (e, em certo sentido, denunciado ou acusado publicamente) como seita.

O perigo é então representado pela proliferação de discursos e práticas que se pretendem como opções, propondo sistemas de valores capazes de responder às expectativas existenciais das pessoas, tão legítimas quanto as outras. Esta indeterminação institucional provoca o medo e as suspeitas, e gera a arena onde os discursos se opõem.

Este conjunto difuso e vago, difícil de conceitualizar, se resume, finalmente, numa vontade de efetuar uma diferenciação entre os grupos religiosos e as seitas. O termo seita é a ferramenta de classificação privilegiada, utilizada num processo constante que consiste em tentar identificar e enquadrar neste conjunto nebuloso os grupos considerados como podendo causar prejuízos ao cidadão. O perigo é compreendido exatamente como esta incapacidade em definir o bom e o mau grupo agindo no seio da sociedade.

${ }^{17}$ Geertz, Clifford. (1986 : 95).

${ }^{18}$ Pétonnet, Colette. .(1979).

${ }^{19}$ Bourdieu, Pierre. (1980:21). 
Neste contexto, as questões relativas à escolha/opção religiosa se colocam como centrais. Pretendi compreender, junto aos eckistas, as razões de seu pertencimento e o lugar de Eckankar no seio do panorama contemporâneo da sociedade francesa. Este lugar é o de uma alternativa que responde às expectativas de bem estar e de bem viver dos eckistas.

Eckankar se constitui em oposição às formas de conhecimento de si oferecidas pelas opções científicas como as terapias psicológicas e psiquiátricas. Enquanto local de um exercício de autoconhecimento, Eckankar transpõe as fronteiras das possibilidades oferecidas pela ciência e pela razão. Ao mesmo tempo, Eckankar é uma alternativa à outros sistemas filosóficos e outras vias espirituais como o hinduismo, o budismo, o islã e o cristianismo.

Se a doutrina eckista inspira claramente o conjunto de suas noções nas tradições esotéricas e ocultistas historicamente datadas, os eckistas em Paris fazem uma interpretação especialmente original e pragmática, ligada as suas trajetórias de vida e aos problemas afrontados no quotidiano. Re-significações dos princípios doutrinais são assim efetuados pela comunidade a partir das experiências da vida de todos os dias, de uma maneira dinâmica e criativa. É assim que os eckistas atualizam os conceitos doutrinais, o que é possível uma vez que Eckankar apresenta uma estrutura extremamente maleável, que permite a incorporação das experiências vivenciadas por indivíduos originários de vários países e culturas diferentes ${ }^{20}$.

A ética eckista é individualista, centrada sobre o axioma da existência da alma que conforma a identidade de cada adepto. Noções paralelas e complementares, tais como as vidas passadas e o karma dão a cada eckista uma grade de leitura significativa que lhe permite ler o mundo (no passado como no presente) e de agir sobre a sociedade no seu quotidiano.

As principais práticas eckistas consistem na análise coletiva das viagens de alma efetuadas durante os sonhos e as contemplações. Trata-

\footnotetext{
${ }^{20}$ À diferença de outras regiões da França, a comunidade eckista em Paris é composta igualmente por pessoas oriundas de outros países europeus (Bélgica e Itália) e africanos (Benin e Togo). Esta observação foi feita por dois eckistas.
} 
se, portanto, de práticas individuais, subjetivas e interiores. Entretanto, a leitura da significação destas práticas é o fruto de um trabalho de socialização das emoções e de aprendizagem dos conceitos da doutrina eckista. Este trabalho se faz coletivamente, os encontros eckistas servindo na coesão das crenças e das interpretações dos acontecimentos do quotidiano. Se o estudo e a leitura são atividades individuais, a significação destes conceitos é organizada coletivamente, o eixo repousando sobre a oralidade e a partilha de depoimentos ${ }^{21}$.

$\mathrm{Na}$ medida em que Eckankar apresenta-se como a religião da Luz e do Som de Deus, o adepto aprende à perceber o mundo segundo um quadro de leitura de significados oferecida: ele aprende a ver o que é visível no imaginário eckista e a escutar os sons, significativos porque determinados por um universo de senso específico. Aliás, o verdadeiro mundo para o eckista é aquele dos planos da alma, superiores aos planos representados pela razão, pela matéria e pelas opções espirituais existentes: o mundo «aqui de baixo» é uma escola, uma etapa necessária na evolução espiritual do adepto, e outras etapas seguirão no futuro.

Neste sentido, o eckista esforça-se para vencer as cinco paixões humanas citadas anteriormente, sendo a mais importante dentre estas a capacidade de desapego. Este é considerado em seu sentido mais amplo: desapego às pessoas assim como às noções que anteriormente balizaram a vida de cada eckista (percebido como rompimento com as formas de pensar o mundo anterior ao encontro com Eckankar). O amor é um conceito central na ética eckista, mas caracteriza-se por uma necessidade premente de não se estabelecerem laços que restringiriam o desenvolvimento livre de cada alma. Amar de forma apegada é uma paixão inferior e material, podendo inclusive influir no karma de cada um. Como exemplo desta concepção relembro uma cena que vivi quando, acompanhada por uma eckista, comentei sobre um alcoólatra que passava pela rua. Meu sentimento de desconforto frente a este homem foi rapidamente contestado; afinal, explicava-me minha acompanhante, se ele estava nesta situação era em função de seu

${ }^{21}$ A bibliografia produzida por Paul Twitchell apresenta mais de uma dezena de títulos, bem como a de Harold Klempt. 
próprio karma ou de um karma familiar. O fato de me entristecer por esta cena demonstrava o quanto eu não sabia amar sem apego, o que, além de assinalar minha baixa evolução espiritual, poderia ainda ser perigoso: eu poderia « pegar » o karma desta pessoa.

O verdadeiro mundo para o eckista não é portanto aqui, ele encontra-se em outro lugar. É o mundo do divino, onde a alma se encontrava antes do nascimento e em direção à qual ela retornará após a morte: são os planos invisíveis e superiores. A identidade da alma assim encontrada/definida é o fundamento da identidade eckista. O conhecimento desta realidade metafísica confere ao eckista a possibilidade de superar as limitações impostas aos seres humanos, quais sejam, aquelas relativas ao nascimento e à morte. Graça às respostas que Eckankar propõe às questões fundamentais da existência, o eckista pode realizar as viagens da alma, verdadeiras experiências controladas de deslocamento da alma. A alma da pessoa que conheceu Eckankar e se desenvolveu espiritualmente não re-encarna mais ; portanto, de uma certa maneira, ela não morre jamais: seu destino é o de se tornar um «trabalhador associado à Deus» e de efetuar o trabalho de co-criação do universo.

A pessoa eckista participa de um mundo globalizado ${ }^{22}$, onde os pertencimentos étnicos ou nacionais contam menos que aqueles que identificam a comunidade formada pelas almas que já conheceram as verdades espirituais. O trânsito e o fluxo são característicos deste pertencimento religioso dinâmico, onde a mobilidade se exprime através das representações do corpo e da alma: estabelece-se assim uma cartografia espiritual, um espaço de deslocamento que só os eckistas conhecem e tem o direito de percorrer. Marguerite, entrelaçando sua história de vida à Eckankar, assim nos relata:

(...) "Eu tinha 49 anos quando pude me aproximar desta coisa que eu conhecia desde a minha infância. Mas eu não sabia o que era, eu não sabia o nome, eu tinha medo às vezes. Tem-se medo deste som nas orelhas, vamos ver o médico por isso, tem-se medo

${ }^{22}$ Ver Mary, André. (2000) ; Appadurai, (2001) e Bastian, J. P., Champion, F. et Rousselet, K. (2001). 
quando fechamos os olhos e vemos grandes clarões, tem-se medo... Porque nós estamos no domínio da consciência humana,e que pouco a pouco... Felizmente que Paul Twitchell teve a boa idéia de se encarnar, porque foi ele quem abriu, em 1965, e ele escreveu estes livros que fizeram com que, nós, os pesquisadores, os conhecedores, nós conhecemos este som e esta luz,mas não sabíamos o que era. Enfim nós pudemos nos reunir! Nós sabemos, nós conhecemos tudo isso desde a infância e, enfim, a gente reconhece. Nós não somos loucos! Como quando eu conheci a Atlântida, você pensa que foi engraçado? Eu não podia falar nem à minha família nem aos meus amigos! E enfim eu encontrei o Mestre, que me levou lá para me mostrar tudo isso“.

No curso desta pesquisa as questões relativas ao universo do domínio religioso legítimo ou não apareceram tanto como categorias de acusação quanto de afrontamento aos olhos dos sujeitos envolvidos pelo debate: este campo é polêmico e freqüentemente designado como passional $^{23}$.

Considero, portanto, que Eckankar se situa como um espaço onde se operam as escolhas e opções de crenças, espaço este de natureza positiva. Esta postura difere do discurso dominante que considera os adeptos das seitas (e principalmente, os ex-adeptos) como vítimas, de forma negativa. Longe de ser o traço distintivo de uma falta ou ausência das capacidades intelectuais ou emocionais dos indivíduos, a adesão a Eckankar apresenta-se como uma opção entre outras. Além disto, a plasticidade e a flexibilidade do sistema de representações de Eckankar permite aos adeptos vindos de origens diversas, com bagagens culturais específicas, de se reencontrar e de estabelecer laços de identidade, de sociabilidade e de organização de valores que guiam suas relações com os outros e com o mundo. Longe de ser uma sobrevivência irracional de idéias tidas como bizarras, a adesão a Eckankar aporta à seus membros maneiras de refletir sobre suas existências no contexto de uma sociedade moderna e globalizada.

${ }^{23}$ Champion, F. et Cohen, M. (1999) e Hervieu-Léger, D. (2001). 


\section{Referências bibliográficas}

APPADURAI, Arjun. Après le colonialisme. Les conséquences culturelles de la globalisation. Paris, Payot, 2001.

Assemblée Nationale, Rapport fait au nom de la commission d'enquête sur les sectes. Président: M. Alain GEST, rapporteur: M. Jacques GUYARD, député - 10 janvier 1996.

Bastian, Jean-Pierre, Champion, Françoise et Rousselet, Kathy. (sous la direction de) La globalisation du religieux. Paris, l'Harmattan, 2001.

BIRMAN, Patricia. Entre França et Brasil : viagens antropológicas num campo (religioso) minado. In: Horizontes Antropológicos $n^{\circ} 10$, maio de 1999.

BIRMAN, Patricia. Multiculturalité religieuse en France : vers un nouvel Orient ?. In: Ethnologie Française. XXX, 2000, 4.

Birman, Patricia, Novaes, Regina \& Crespo, Samira. (org.) O mal à brasileira. Ed. UERJ, Rio de Janeiro, 1997.

BOURDIEU, Pierre. Genèse et structure du champ religieux. In: Revue Française de Sociologie. XII, 1971.

BOURDIEU, Pierre. Le champ scientifique. In: Actes de la recherche en sciences sociales, $\mathrm{n}^{\circ} 2 / 3$, juin 1976.

BOURDIEU, Pierre. Le nord et le midi : contribution à une analyse de l'effet Montesquieu. In: Actes de la recherche en sciences sociales, $\mathrm{n}^{\circ}$ 35, nov. 1980.

Champion, Françoise \& COHEN, Martine. Sectes et Démocratie. Editions du Seuil, 1999.

Champion, Françoise \& Hervieu-LÉGer, Danièle. De l'émotion en religion. Renouveaux et Traditions. Centurion: Paris, 1990. 
Dubuisson, Daniel. L'Occident et la religion. Mythes, science et idéologie. Ed. Complexe, 1998.

GEERTZ, Clifford. «Le sens commun en tant que système culturel ». In: Savoir Local, Savoir Global. Les Lieux du Savoir. Paris, P.U.F., 1986.

GIUMBELLI, Emerson. O fim da religião: controvérsias acerca das «seitas » e da «liberdade religiosa » no Brasil e na França. Tese de Doutorado. Rio de Janeiro, Museu Nacional, 2000.

HERVIEU-LÉGER, Danièle. La religion en miettes ou la question des sectes. Calman-Lévy, 2001.

MARY, André. "L'anthropologie au risque des religions mondiales ». In: Anthropologie et sociétés, vol: 24, n 1, 2000.

Mauss, Marcel. «Les Techniques du Corps» In: Sociologie et anthropologie, Paris, PUF, 1983.

MESSNER, François. «La législation cultuelle des pays de l'Union européenne face aux groupes sectaires ». In: CHAmpion, Françoise. \& CoHen, Martine. Sectes et Démocratie. Paris, Seuil, 1999.

PÉTONnet, Colette. On est tous dans le brouillard. Ethnologie des banlieues. Paris, Editions Galilée, 1979.

Piault, Marc Henri. Anthropologie et Cinéma. Passage à l'image, passage par l'image. Paris, Nathan, 2000

Rodolpho, Adriane Luisa. Les Voyageurs de l'Âme. Etude Ethnologique auprès du groupe Eckankar France - Paris. Thèse de Doctorat. Paris : EHESS, 2002.

STOCZKowsKI, Wiktor. Anthropologie naïve, anthropologie savante. De l'origine de l'homme, de l'imagination et des idées reçues. CNRS Editions, 1994.

Stoczkowski, Wiktor. Des hommes, des dieux et des extraterrestres. Ethnologie d'une croyance moderne. Paris, Flammarion, 1999.

Twitchell, Paul. Shariyat-Ki-Sugmad, Primeiro Livro. Eckankar, Minneapolis, MN,USA, 1970 
Twitchell, Paul. Shariyat-Ki-Sugmad, Segundo Livro. Eckankar, Minneapolis, MN,USA, 1971.

ZEMPLENI, Andreàs. «Initiation», in Pierre BonTÉ et Michel IZARD (éd.), Dictionnaire de l'ethnologie et de l'anthropologie. Paris, PUF, 1991. 